\title{
Discrepancies Between Planned and Actual Operating Room Turnaround Times at a Large Rural Hospital in Germany
}

Regula Morgenegg, ${ }^{1}$ Franziska Heinze, ${ }^{2}$ Katharina Wieferich, ${ }^{2}$ Ralf Schiffer, ${ }^{2}$ Frank Stueber, "Markus M. Luedi, ${ }^{1}$ Dietrich Doll ${ }^{3}$

$$
\text { التناقضات بين أوقات التحول الفعلية و المخطط لها في غرف العمليات في في ألمانيا }
$$

ريجولا مورجينيخ، فرانزيسكا هاينز، كاثارينا ويفريش، رالف شيفر، فرانك ستيبر، ماركوس لويدي، ديتريش دول

ABSTRACT: Objectives: While several factors have been shown to influence operating room (OR) turnaround times, few comparisons of planned and actual OR turnaround times have been performed. This study aimed to compare planned and actual OR turnaround times at a large rural hospital in Northern Germany. Methods: This retrospective study examined the OR turnaround data of 875 elective surgery cases scheduled at the Marienhospital, Vechta, Germany, between July and October 2014. The frequency distributions of planned and actual OR turnaround times were compared and correlations between turnaround times and various factors were established, including the time of day of the procedure, patient age and the planned duration of the surgery. Results: There was a significant difference between mean planned and actual OR turnaround times $(0.32$ versus 0.64 hours; $P<0.001)$. In addition, significant correlations were noted between actual OR turnaround times and the time of day of the surgery, patient age, actual duration of the procedure and staffing changes affecting the surgeon or the medical specialty of the surgery $(P<0.001$ each). The quotient of actual/planned OR turnaround times ranged from 1.733-3.000. Conclusion: Significant discrepancies between planned and actual OR turnaround times were noted during the study period. Such findings may be potentially used in future studies to establish a tool to improve OR planning, measure OR management performance and enable benchmarking.

Keywords: Operating Room, organization and administration; Patient Care Management; Strategic Planning; Time Management; Quality Control; Germany.

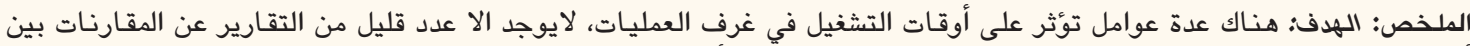

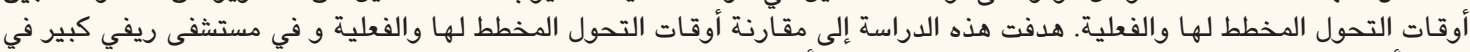

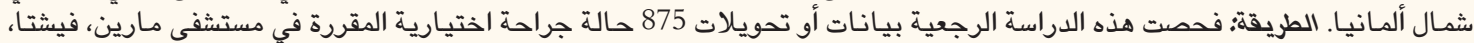

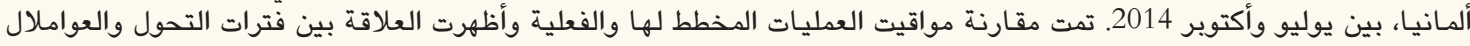

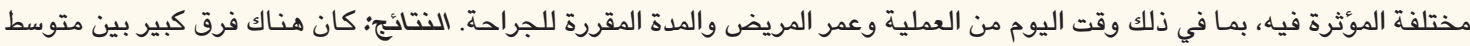

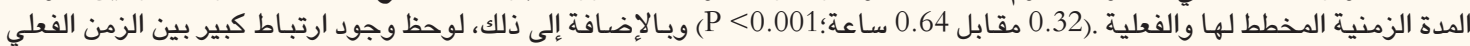

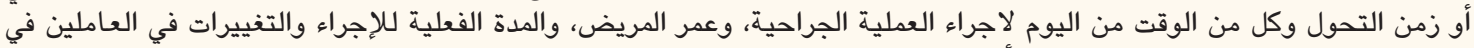

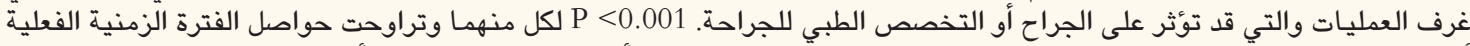

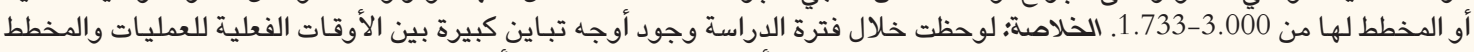

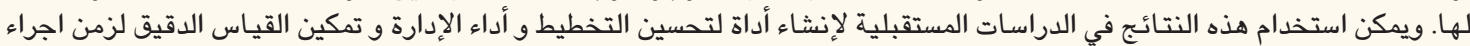
العمليات الجراحية واستخدام غرف العت العمليات العنات

الكلمات المفتاحية: غرف العمليات، التنظيم والإدارة؛ إدارة رعاية المرضى؛ التخطيط الأستراتيجي؛ إدارة الوقت؛ مراقبة الجودة؛ ألمانيا.

\section{AdVANCES IN KNOWLEDGE}

This study identified significant discrepancies between planned and actual operating room (OR) turnaround times at a large rural hospital in Northern Germany.

\section{Application to Patient Care}

The findings of the current study could potentially be used to improve OR planning and management and provide a reference point for optimal OR turnaround times. The correction of any discrepancies between planned and actual OR turnaround times can reduce patient wait times and increase OR optimisation by allowing more surgeries to be performed in a specific OR. 
$\mathrm{O}$ RGANISATIONAL DECISIONS RELATED TO THE planning of surgeries are based on a series of hierarchical priorities, including patient safety, the surgeon's access to an available operating room (OR), OR efficiency and patient wait times. ${ }^{1}$ In contrast, longer-term strategic decisions focus on increasing OR capacity utilisation despite potential uncertainties in future caseloads. ${ }^{2}$ The interval between the end of one surgery on a patient and the beginning of the next surgery on another patient is known as the OR turnaround time; this should be distinguished from OR turnover time which conventionally indicates the interval between the previous patient leaving the OR and the next patient entering the room, although these terms are sometimes used interchangeably. ${ }^{3-6}$

Various factors have been shown to influence OR turnaround times; for example, the time of day of the surgery, the age and American Society of Anesthesiology physical status of the patient and the assignment of the right anaesthesiologist to a surgeon have all been associated with a reduction in OR overutilisation. $^{4,5,7,8}$ In contrast, a change in surgeon has been found to have no significant impact on OR efficiency. ${ }^{9}$ In an in-depth analysis of OR data, including causes of delays and personal accountability, Overdyk et al. found that teamwork improved OR efficiency. ${ }^{10}$ However, Masursky et al. observed that both surgeons and, to a lesser extent, anaesthesiologists, judged OR turnaround times according to mental models of factors influencing turnover; thus, the perceptions of surgeons or anaesthesiologists should not be relied upon to make OR management decisions. ${ }^{11}$ A direct comparison between planned and actual OR turnaround times is useful as any discrepancies between the two times can affect OR efficiency. To this end, the current study aimed to compare factors influencing planned and actual OR turnaround times at a large hospital in Vechta, Northern Germany.

\section{Methods}

This retrospective study was conducted at the Marienhospital, a rural 321-bed hospital with six ORs in Vechta. ${ }^{4,5}$ The OR data of elective surgical cases scheduled at the Marienhospital between July and October 2014 were analysed. Only those elective surgeries under the following medical specialties were included: general surgery; orthopaedic/trauma surgery; visceral surgery (including coloproctologyrelated procedures); ear, nose and throat (ENT) surgery; obstetrics and gynaecology surgery; dermatology surgery; and internal medicine surgery (including the surgical implantation of cardiac pacemakers). Information related to the surgeries, patients and OR turnaround times was retrieved from the hospital's electronic information system (Orbis Krankenhaus-Informationssystem, Bureau van Dijk, Amsterdam, the Netherlands).

During the study period, 2,651 OR procedures were recorded in the hospital's electronic database. Of these, 28 were duplicate entries and 225 cases were scheduled in an OR reserved for preparatory and/or poorly documented procedures. Another 550 cases were excluded because they were performed during public holidays. Of the remaining cases, 426 were unplanned emergency surgeries and 207 were surgeries which were planned but not performed, resulting in 1,215 cases. However, 320 surgeries were the first cases of the day and were therefore excluded as turnaround time could not be determined. An additional 14 surgeries were excluded as they were deemed to be delayed, with turnaround times longer than 90 minutes or deviating more than 15 minutes from the median. ${ }^{8,12}$ Finally, six cases were excluded because they were emergency cases which began at night but continued into the next day. Accordingly, a total of 875 surgeries were included in the final analysis.

The statistical analyses were performed using an Excel spreadsheet, Version 2010 (Microsoft Inc., Redmond, Washington, USA) and GraphPad Prism software, Version 6.0 (GraphPad Software Inc., La Jolla, California, USA). Results derived from twotailed t-tests were considered significant at the level of $P<0.050$. Non-parametric testing was employed as the specific grouping of cases according to surgical lists and time would further decrease the sample size. A Chi-squared test was used to compare frequency distributions and planned and actual OR turnaround times were correlated using Wilcoxon and MannWhitney U tests. The Kruskal-Wallis test was utilised to correlate turnaround times with the specific time of day at hourly intervals. Correlations between planned and actual OR turnaround times and patient age and the duration of surgery were determined according to Spearman's rank correlation.

This study was approved by the Ethics Committee of the Medical Association of Lower Saxony, Hanover, Germany, as per their professional code of conduct. Formal ethical approval was waived as the patients were neither psychologically nor physically affected by the study.

\section{Results}

The mean planned OR turnaround time was 0.32 hours (95\% confidence interval [CI]: 0.30-0.33 hours); in contrast, the mean actual OR turnaround time differed significantly at 0.64 hours (95\% CI: $0.62-0.65$ hours; 

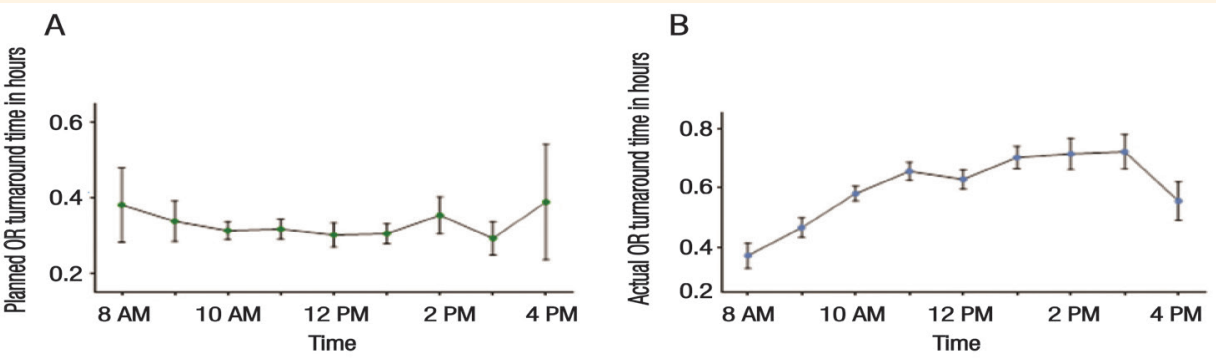

Figure 1: Mean (A) planned and (B) actual operating room turnaround times according to time of day* among elective surgical cases scheduled at a large rural hospital in Northern Germany $(\mathrm{N}=875)$.

$O R=$ operating room

*Data at specific hours include the preceding 60 minutes.

$P<0.001)$. Actual OR turnaround times exceeded planned times in 773 cases (88.3\%), while they fell short of planned times in 93 cases (10.6\%) and were exactly the same in nine cases (1.0\%). No significant relationship was found between planned OR turnaround times and the time of day of the procedure $(P=0.444)$. However, actual OR turnaround times increased significantly as the day progressed, increasing on average from 0.37 to 0.72 hours between $8 \mathrm{AM}$ and $3 \mathrm{PM}$ before dropping back to 0.56 hours at $4 \mathrm{PM}(P=0.001)$ [Figure 1].

In addition, while no correlation was noted between planned OR turnaround time and patient age $(r=0.0163 ; P=0.622)$, there was a significant relationship between planned OR turnaround time and the planned duration of the procedure $(r=0.0767$; $P=0.020$ ) [Figures $2 \mathrm{~A}$ and $\mathrm{B}$ ]. In contrast, actual OR turnaround times correlated significantly with both patient age $(\mathrm{r}=0.2375 ; P<0.001)$ and the actual duration of the procedure $(\mathrm{r}=0.5114 ; P<0.001)$ [Figures $2 \mathrm{C}$ and D]. Significant discrepancies between planned and actual OR turnaround times were noted among all medical specialties, with discrepancies ranging from 3.4-fold for dermatology surgeries to 1.7-fold for ENT surgeries [Figure 3].

Correlations between changes in staffing and discrepancies in planned and actual OR turnaround times were assessed. The mean actual OR turnaround time was 0.59 hours when there was no change in either the surgeon performing the procedure or the specialty of the surgery. No significant differences in planned OR turnaround time were observed with either a change of surgeon within the same medical specialty $(P=0.140)$ or a change in medical specialty entirely $(P=0.752)$. However, the mean actual OR turnaround time differed significantly with either a change in surgeon ( 0.67 hours versus 0.59 hours; $P<0.001)$ or a change in medical specialty $(0.87$ hours versus 0.59 hours; $P<0.001$ ) [Figure 4]. Quotients of planned and actual OR turnaround times were generated according to medical specialty, excluding 49 cases with a planned turnaround time of 0 as this is impossible in reality although obtainable in theoretical
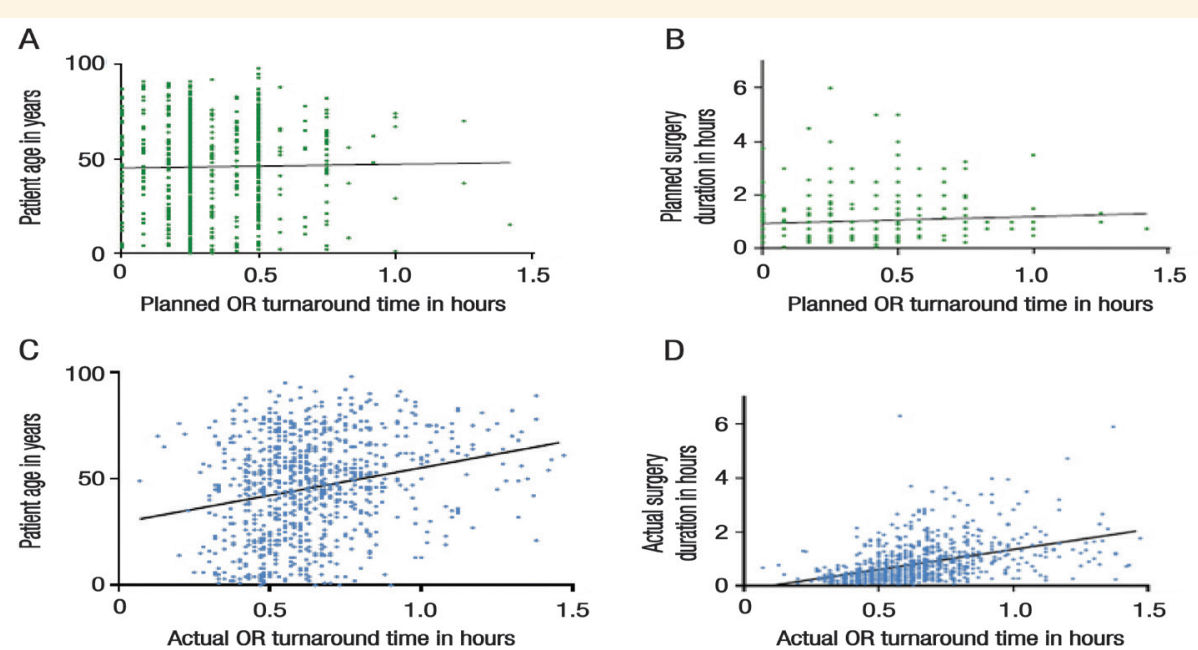

Figure 2: Correlations between mean (A \& B) planned and (C \& D) actual operating room turnaround times and patient age and duration of surgery, respectively, among elective surgical cases scheduled at a large rural hospital in Northern Germany $(\mathrm{N}=875)$.

$O R=$ operating room. 
A

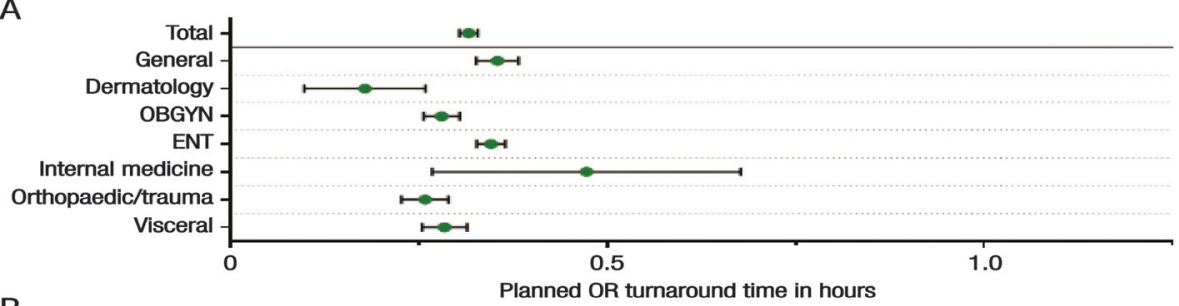

B

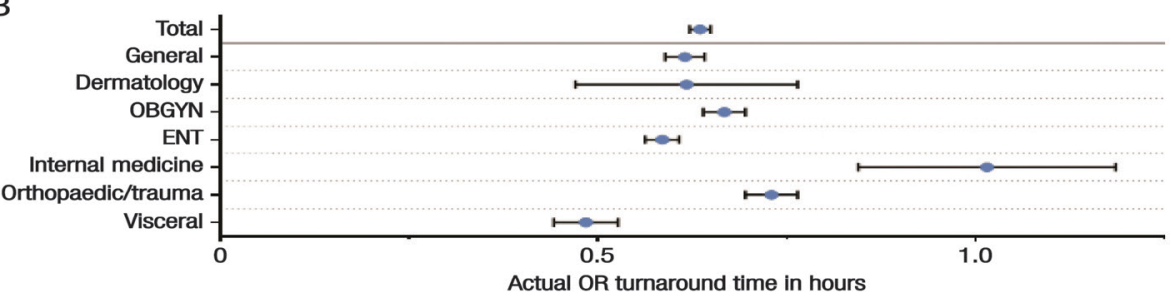

Figure 3: Mean (A) planned and (B) actual operating room turnaround times according to medical specialty among elective surgical cases scheduled at a large rural hospital in Northern Germany $(\mathrm{N}=875)$. The error bars represent $95 \%$ confidence intervals.

$O B G Y N=$ obstetrics and gynaecology; $E N T=$ ear, nose and throat; $O R=$ operating room .
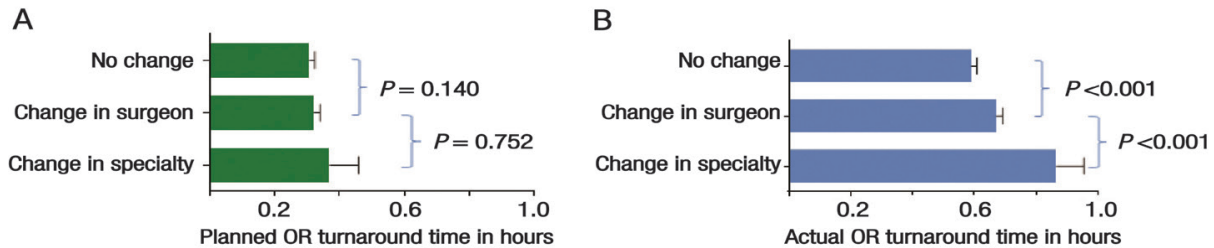

Figure 4: Correlations between mean (A) planned and (B) actual operating room turnaround times and staffing changes (i.e. either a change in surgeon or the medical specialty of the surgery) among elective surgical cases scheduled at a large rural hospital in Northern Germany $(\mathrm{N}=875)$.

$O R=$ operating room.

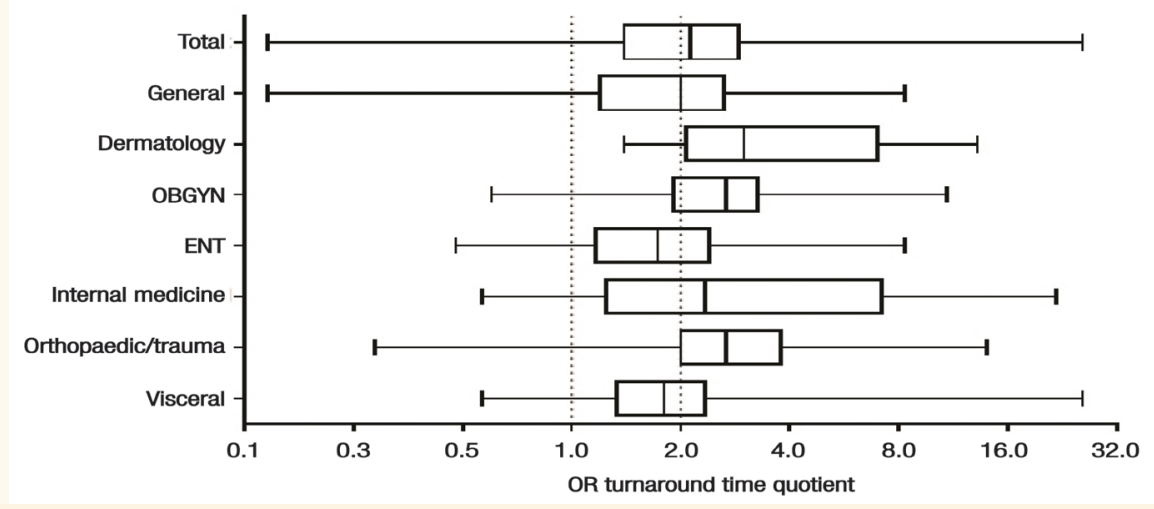

Figure 5: Boxplots of quotients of actual and planned operating room turnaround times according to specialty among elective surgical cases scheduled at a large rural hospital in Northern Germany $(\mathrm{N}=826)^{*}$. The boxplots are presented on a $\log 2$ scale.

$O B G Y N=$ obstetrics and gynaecology; $E N T=$ ear, nose and throat; $O R=$ operating room.

*Total data set for this variable was 826 as 49 cases were excluded.

planning. Of the remaining 826 cases, median quotients ranged from 1.733 for ENT surgeries to 3.000 for dermatology surgeries. None of the specialties achieved a perfect mean quotient of 1.0 [Figure 5].

\section{Discussion}

Significant discrepancies were found between planned and actual OR turnaround times in the current study. These discrepancies correlated with the time of day 
of the procedure, patient age, actual duration of the procedure and staffing changes. The observed correlations between prolonged turnaround times and both time of day and patient age were in line with previously described findings. ${ }^{4,7}$ However, Austin et al. determined that a change in surgeon had a negligible effect on OR turnover time. ${ }^{9}$ Despite evidence that these individuals hold much of the responsibility for procedural efficiency, Masursky et al. previously found that surgeons were biased when it came to planning OR turnaround times. ${ }^{11,13}$

Correcting discrepancies between planned and actual OR turnaround times can reduce patient wait times, potentially enabling more procedures to be performed in a single OR, especially when numerous short surgeries are scheduled. The findings of the current study have potential managerial applications at the Marienhospital in order to increase the accuracy of OR planning and measure OR efficiency; in addition, these results can be used as a yardstick against which future data can be benchmarked. ${ }^{14}$ Further investigations are planned to develop a tool incorporating those factors found to significantly impact OR turnover times in the current study. Nevertheless, it remains a matter of debate as to whether statistical analyses such as those utilised in the present study will accurately assess nonmathematical factors. For example, there is evidence that financial incentive programmes, interviews with stakeholders and the assignment of an appropriate anaesthesiologist can influence turnaround times. ${ }^{5,15,16}$ Moreover, psychological factors such as emotional intelligence may affect patient safety as well as perioperative performance..$^{17,18}$

This study is subject to certain limitations. Other variables potentially affecting OR turnaround time were not included in the current analysis, such as variations in OR cleaning needs, patient transportation, the individual experience of the surgeon, the availability of senior surgical team members during a procedure, the specialties of other personnel present (e.g. surgeons, anaesthesiologists and nurses) and the use of operative devices/materials requiring extra preparation time. In addition, the study was limited by its retrospective nature; as such, the correlations observed are not definitive proof of causation. It is likely that certain correlations were only marginally significant due to their small sample sizes (e.g. OR turnaround times for dermatology and internal medicine surgeries were based on 14 and 15 cases, respectively). Additionally, while the results of this study can be used to improve the accuracy of OR planning at the Marienhospital, they cannot be extrapolated to other hospitals. Nevertheless, the findings of this study are supported by the fact that discrepancies between planned and actual OR turnaround times were identified and correlations found with most parameters.

\section{Conclusion}

Significant discrepancies between planned and actual OR turnaround times were observed in the current study. Moreover, actual OR turnaround times were significantly affected by the time of day of the surgery, patient age, actual duration of the procedure and staffing changes. These findings have important managerial implications and may be used by OR managers to increase the accuracy of OR planning, measure OR performance and enable potential benchmarking. Future investigations are planned to construct a tool to accommodate identified factors impacting OR turnover times.

\section{CONFLICT OF INTEREST}

The authors declare no conflicts of interest.

\section{FUNDING}

No funding was received for this study.

\section{References}

1. Dexter F, Epstein RH, Traub RD, Xiao Y. Making management decisions on the day of surgery based on operating room efficiency and patient waiting times. Anesthesiology 2004; 101:1444-53. doi: 10.1097/00000542-200412000-00027.

2. Dexter F, Ledolter J, Wachtel RE. Tactical decision making for selective expansion of operating room resources incorporating financial criteria and uncertainty in subspecialties' future workloads. Anesth Analg 2005; 100:1425-32. doi: 10.1213/01. ANE.0000149898.45044.3D.

3. Sandberg WS, Daily B, Egan M, Stahl JE, Goldman JM, Wiklund RA, et al. Deliberate perioperative systems design improves operating room throughput. Anesthesiology 2005; 103:406-18. doi: 10.1097/00000542-200508000-00025.

4. Luedi MM, Kauf P, Mulks L, Wieferich K, Schiffer R, Doll D. Implications of patient age and ASA physical status for operating room management decisions. Anesth Analg 2016; 122:1169-77. doi: 10.1213/ANE.0000000000001187.

5. Luedi MM, Doll D, Boggs SD, Stueber F. In response. Anesth Analg 2017; 124:1738-9. doi: 10.1213/ANE.0000000000001999.

6. Association of Anesthesia Clinical Directors. Glossary of times used for scheduling and monitoring of diagnostic and therapeutic procedures. AORN J 1997; 66:601-6. doi: 10.1016/ S0001-2092(06)62913-X.

7. Doll D, Wieferich K, Erhart T, Hoenemann C. Waiting for Godot: An analysis of 2622 operating room turnover times. Eur J Anaesthesiol 2014; 31:388-9. doi: 10.1097/EJA.0000000 000000059.

8. Dexter F, Epstein RH, Marcon E, Ledolter J. Estimating the incidence of prolonged turnover times and delays by time of day. Anesthesiology 2005; 102:1242-8. doi: 10.1097/00000542200506000-00026. 
9. Austin TM, Lam HV, Shin NS, Daily BJ, Dunn PF, Sandberg WS. Elective change of surgeon during the OR day has an operationally negligible impact on turnover time. J Clin Anesth 2014; 26:343-9. doi: 10.1016/j.jclinane.2014.02.008.

10. Overdyk FJ, Harvey SC, Fishman RL, Shippey F. Successful strategies for improving operating room efficiency at academic institutions. Anesth Analg 1998; 86:896-906. doi: 10.1213/ 00000539-199904000-00057.

11. Masursky D, Dexter F, Isaacson SA, Nussmeier NA. Surgeons' and anesthesiologists' perceptions of turnover times. Anesth Analg 2011; 112:440-4. doi: 10.1213/ANE.0b013e3182043049.

12. Dexter F, Abouleish AE, Epstein RH, Whitten CW, Lubarsky DA. Use of operating room information system data to predict the impact of reducing turnover times on staffing costs. Anesth Analg 2003; 97:1119-26. doi: 10.1213/01.ANE.000008 2520.68800 .79 .

13. Fong AJ, Smith M, Langerman A. Efficiency improvement in the operating room. J Surg Res 2016; 204:371-83. doi: 10.1016/j. jss.2016.04.054.
14. Helkiö P, Aantaa R, Virolainen P, Tuominen R. Productivity benchmarks for operative service units. Acta Anaesthesiol Scand 2016; 60:450-6. doi: 10.1111/aas.12676.

15. Scalea TM, Carco D, Reece M, Fouche YL, Pollak AN, Nagarkatti SS. Effect of a novel financial incentive program on operating room efficiency. JAMA Surg 2014; 149:920-4. doi: 10.1001/jamasurg.2014.1233.

16. Pimentel MT, Flanagan H, Philip BK, Urman RD. Qualitative analysis of barriers to efficient operating room turnovers in a tertiary care academic medical center. J Med Pract Manag 2015; 30:30-5.

17. Luedi MM, Boggs SD, Doll D, Stueber F. On patient safety, teams and psychologically disturbed pilots. Eur J Anaesthesiol 2016; 33:226-7. doi: 10.1097/EJA.0000000000000403.

18. Luedi MM, Doll D, Boggs SD, Stueber F. Successful personalities in anesthesiology and acute care medicine: Are we selecting, training, and supporting the best? Anesth Analg 2017; 124:359-61. doi: 10.1213/ANE.0000000000001714. 